SISTEMA
ELETROANICO
DE REVISTAS
SER I UfPR

\title{
Base ecossistêmica para o ordenamento territorial na planície costeira do Rio Grande do Sul
}

\section{Ecosystem Base for Land-Use Planning in the Coastal Plain of Rio Grande do Sul}

\author{
Paulo Roberto Armanini TAGLIANI ${ }^{1 *}$ \\ ${ }^{1}$ Universidade Federal do Rio Grande (FURG), Rio Grande, RS, Brasil. \\ *E-mail de contato: paulotagliani16@gmail.com
}

Artigo recebido em 31 de agosto de 2017, versão final aceita em 9 de novembro de 2017.

\begin{abstract}
RESUMO: O número de pesquisas relativas a funções e serviços ecossistêmicos tem aumentado de forma quase exponencial nas últimas décadas, o que denota a importância que a comunidade científica vem atribuindo ao reconhecimento da manutenção da base ecossistêmica no atendimento das demandas da sociedade. Na porção terrestre das zonas costeiras, tais demandas usualmente recaem sobre a oferta de espaço para os desenvolvimentos turístico, urbano, portuário, agrícola, da aquacultura, dos florestamentos, da pecuária e da mineração, entre outros. A crescente conversão de habitats para tais usos tem sido apontada como a maior ameaça a esses ecossistemas. Portanto, o primeiro desafio que se impõe para uma ocupação territorial sustentável é compreender as funções ecossistêmicas presentes em uma determinada região, identificar as áreas mais ou menos sensíveis para o desenvolvimento das distintas atividades humanas, e plasmá-las em um processo de Zoneamento Ecológico Econômico (ZEE). Para tanto, é necessária uma seleção de indicadores apropriados, capazes de resumir a alta complexidade e conectividade dos ecossistemas em um modelo simples e compreensível. Este estudo, desenvolvido na restinga da Lagoa dos Patos, segmento médio da planície costeira do Rio Grande do Sul, apresenta uma proposta metodológica para o ordenamento espacial em zonas costeiras, tendo como princípio a identificação e a manutenção das funções e dos serviços ecossistêmicos. Como resultado, foram definidas três classes de uso para a região de forma a manter suas propriedades estruturais e funcionais, denominadas de Zonas de Preservação Ambiental, Zonas de Conservação e Zonas de Desenvolvimento. Uma vez que a gênese quaternária dessa restinga está associada aos mesmos processos físicos que atuaram na formação da planície costeira do Rio Grande do Sul, propõe-se a aplicação desse método em toda a extensão desta planície costeira, tal como já realizado no município de Rio Grande, às margens do estuário da Lagoa dos Patos.
\end{abstract}

Palavras-chave: planejamento territorial; zonas costeiras; gerenciamento costeiro. 
ABSTRACT: The number of researches related to ecosystem functions and services has increased almost exponentially in the last decades, which indicates the importance that the scientific community has given to the recognition of the maintenance of the ecosystem base in meeting the demands of society. In the terrestrial portion of coastal zones, these demands usually fall on the supply of space for tourism, urban, port, agricultural, aquaculture, forestry, livestock and mining, among others. The increasing conversion of habitats to such uses has been pointed out as the greatest threat to these ecosystems. The first challenge to a sustainable territorial occupation is therefore to understand the ecosystem functions present in a given region, to identify the more or less sensitive areas for the development of different human activities, and to shape them into a process of Economic Ecological Zoning (ZEE, in Portuguese). To do so, a selection of appropriate indicators is needed to summarize the high complexity and connectivity of ecosystems in a simple and understandable model. This study, developed in Lagoa dos Patos Island Barrier, in the middle segment of the coastal plain of Rio Grande do Sul state, presents a methodological proposal for spatial planning in coastal zones, based on the identification and maintenance of ecosystem functions and services. As a result, three classes of use were defined for a region in order to maintain its structural and functional properties, called Environmental Preservation Zones, Conservation Zones and Development Zones. Since the quaternary genesis of this island barrier is associated to the same physical processes that acted in the formation of the coastal plain of Rio Grande do Sul, it is proposed to apply this method in all the extension of this coastal plain, as already done in the municipality of Rio Grande, on margins of the Lagos dos Patos estuary.

Keywords: spatial planning; coastal zones; coastal management.

\section{Introdução}

O número de pesquisas relativas a funções e serviços ecossistêmicos tem aumentado de forma quase exponencial nas últimas décadas (Fisher et al., 2009), o que denota a importância que a comunidade científica vem atribuindo ao reconhecimento da manutenção da base ecossistêmica no atendimento das demandas da sociedade.

Na porção terrestre das zonas costeiras, tais demandas usualmente recaem sobre a oferta de espaço para os desenvolvimentos turístico, urbano, portuário, agropecuário, da aquacultura, da silvicultura, da mineração, entre outros. A crescente conversão de habitats para tais usos tem sido apontada como a maior ameaça a esses ecossistemas (Millennium Ecosystem Assessment, 2005), o que torna premente a busca de sustentabilidade nos processos de ocupação espacial dessas zonas.

O primeiro desafio que se impõe para um ordenamento territorial sustentável é compreen- der as funções ecossistêmicas presentes em uma determinada região, por meio de uma seleção de indicadores apropriados, capazes de resumir a alta complexidade e a conectividade dos ecossistemas em um modelo analítico compreensível, que permita identificar quais as áreas mais ou menos sensíveis para o desenvolvimento das distintas atividades humanas.

Embora ainda persista a demanda por uma sistematização de conceitos sobre funções e serviços ecossistêmicos, tal discussão foge do escopo desse artigo. Adotamos o conceito de "funções" para designar processos ecológicos que mantêm os ecossistemas operando de forma estável, tais como fotossíntese (fixação de bioenergia), estocagem de carbono e nutrientes, estocagem genética (biodiversidade), etc., e o conceito de "serviços ecossistêmicos" como a capacidade do ecossistema (componentes e processos) de prover direta ou indiretamente serviços essenciais para a sociedade. Este estudo apresenta uma proposta metodoló- 
gica para o ordenamento espacial em zonas costeiras, tendo como princípio a identificação e a manutenção das funções e dos serviços ecossistêmicos, tomando-se como exemplo a restinga da Lagoa dos Patos, na planície costeira do sul do Brasil.

\section{2. Área de estudo}

Com uma superfície de aproximadamente $3.700 \mathrm{~km}^{2}$, a Restinga da Lagoa dos Patos constitui-se em uma das maiores restingas brasileiras. Conformando o segmento mediano da planície costeira do Rio Grande do Sul, entre as coordenadas de $30^{\circ} 20^{\prime}$ e $32^{\circ} 10^{\prime}$ de Latitude Sul e $53^{\circ} 53^{\prime}$ e $53^{\circ} 17^{\prime} 05^{\prime}$ ' de Longitude Oeste, compreende os municípios de São José do Norte, Tavares e Mostardas, na costa oriental da Lagoa dos 20 Patos (Figura 1). Ao sul da mesma, já na margem ocidental do estuário que liga a Lagoa dos Patos ao oceano, encontra-se o município do Rio Grande, importante polo turístico, portuário, pesqueiro e industrial do estado. $\mathrm{O}$ município de Mostardas faz divisa ao norte com o pequeno município de Palmares do Sul.

São poucos os estudos modernos realizados na área de estudo. Schwarzbold (1982) estudou a influência da morfologia de várias lagoas da região no balanço de substâncias e na distribuição de macrófitas aquáticas. Loss et al. $(1985 ; 1988 ; 1989)$ e Tomazelli et al. (1988) realizaram o mapeamento geológico na escala de 1:100.000. Long (1989) realizou mapeamento na escala de 1:60.000, com algumas divergências interpretativas. Teixeira \& Neto (1986) realizaram um estudo fitogeográfico englobando a maior parte do Rio Grande do Sul, incluindo a restinga da Lagoa dos Patos. Lanzer \& Schäfer (1987) utilizaram moluscos dulceaquícolas como indicadores de condições tróficas em várias lagoas locais. Scherer \& Petry (2012) realizaram estudos sobre a variação sazonal na comunidade de aves costeiras da região. Villwock (1987) descreveu processos costeiros e a formação de praias arenosas e campos de dunas ao longo da costa sul e sudeste brasileira, incluindo esta região. Cunha (1994) efetuou o levantamento de solos e mapeamento em toda a região, na escala 1:100.000. Informações sobre aspectos socioeconômicos e também arqueológicos e históricos da região podem ser encontradas em Tagliani et al. (2000). Mais recentemente estudos foram conduzidos na Lagoa do Peixe caracterizan-

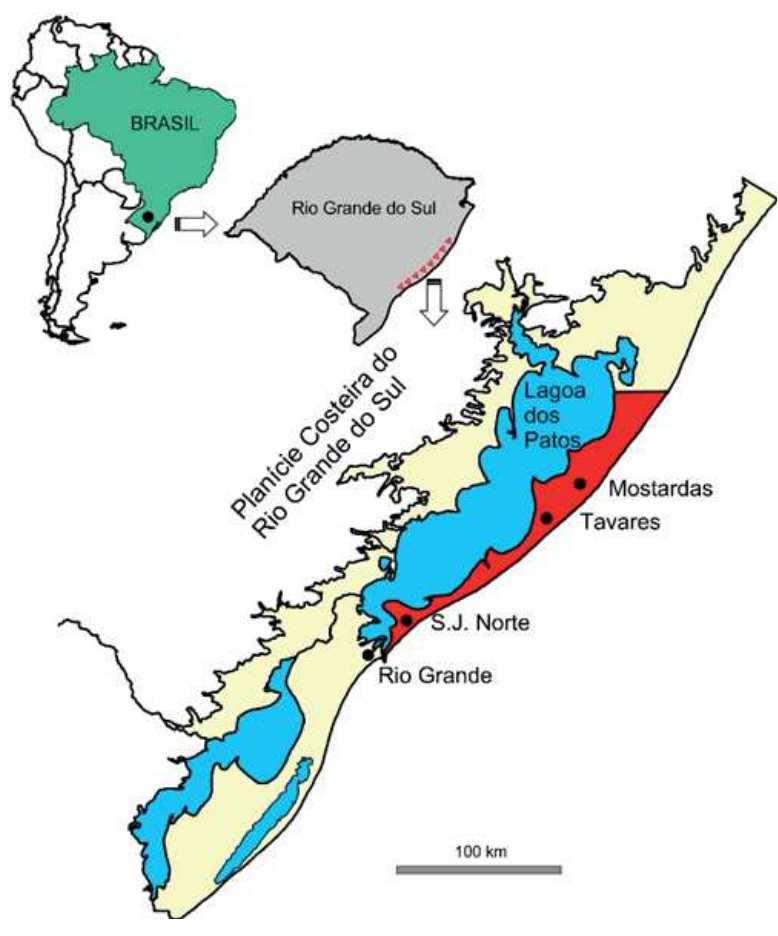

FIGURA 1 - Localização da área de estudo. 
do a fauna de répteis (Loebmann \& Vieira, 2003), anfíbios (Loebmann \& Vieira, 2005a) e peixes e crustáceos decápodos (Loebmann \& Vieira, 2005b; 2005c). Niencheski \& Windom (2015) estudaram as relações entre o aquífero superficial dessa restinga e a qualidade das águas costeiras adjacentes.

\section{Metodologia}

A metodologia empregada parte da identificação e da caracterização das diferentes unidades naturais ou ecotipos que estruturam o sistema, a partir da análise combinada da estrutura geológica/geomorfológica e vegetacional do terreno. As unidades naturais identificadas foram agrupadas em níveis hierárquicos mais amplos (Subsistemas e sistemas) e caracterizadas em relação às principais funções ecossistêmicas presentes e serviços derivados, potenciais ou efetivos em cada unidade. As relações identificadas entre características ambientais e as funções e serviços ecossistêmicos são indicadas na Tabela 1.

Em linhas gerais, este estudo cumpriu os seguintes procedimentos (Figura 2).

\subsection{Identificação das unidades naturais}

A autorregulação ecossistêmica depende de uma infinidade de processos ecológicos em diferentes escalas temporais e espaciais. Tais processos resultam em "ecotipos", ou clusters, de diferentes tamanhos, formas, tipos bióticos e características

TABELA 1 - Relações entre os parâmetros ambientais e funções e serviços ecossistêmicos.

\begin{tabular}{|c|c|c|c|c|c|c|c|c|c|c|c|}
\hline Aspectos selecionados & & 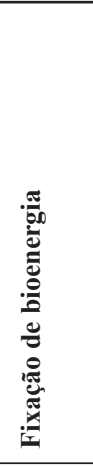 & 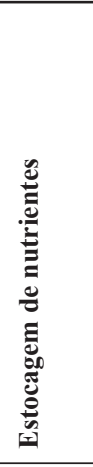 & 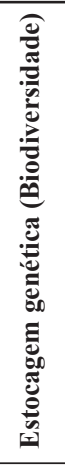 & 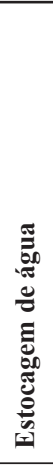 & 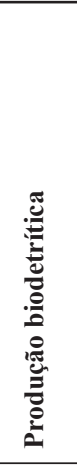 & 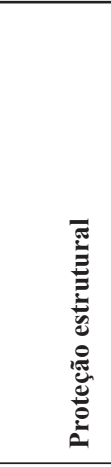 & 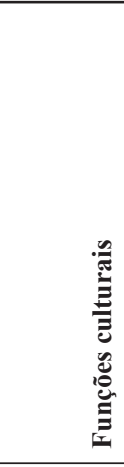 & & 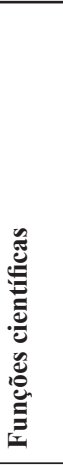 & 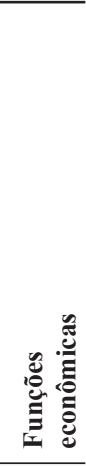 \\
\hline Usos humanos & & & & & & & & $\mathrm{X}$ & $\mathrm{X}$ & $\mathrm{x}$ & \\
\hline Geomorfologia & & & & & & & X & $\mathrm{X}$ & $\mathrm{X}$ & & \\
\hline Fisionomia da vegetação & $\mathrm{X}$ & $\mathrm{X}$ & $\mathrm{X}$ & & & & X & $\mathrm{X}$ & & & \\
\hline $\begin{array}{l}\text { Tipo de } \\
\text { solo }\end{array}$ & & $\mathrm{X}$ & & & & & X & & & y & \\
\hline Lençol freático & & & & & & & & & & r & \\
\hline Diversidade vegetal & & & $\mathrm{X}$ & & & & & $\mathrm{X}$ & $\mathrm{X}$ & & \\
\hline Índice de cobertura vegetal & $\mathrm{X}$ & & & & & & & & & & \\
\hline Biomassa vegetal & $\mathrm{X}$ & $\mathrm{X}$ & & & & & & & & & \\
\hline
\end{tabular}




$$
\begin{aligned}
& \text { Identificação das Unidades Naturais } \\
& \text { Mapeamento e caracterização Mapeamento e caracterização da } \\
& \text { Geológica/geomorfológica Vegetação }
\end{aligned}
$$

FIGURA 2 - Esquema metodológico adotado.

físicas, que se repetem ao longo de uma paisagem, formando um mosaico heterogêneo de manchas ambientais com certo grau de homogeneidade interna e que podem ser detectadas via sensoriamento remoto. Tais manchas constituem sistemas bem estruturados de componentes (rochas, solos, água, biota e clima), complexamente inter-relacionados e controlados por processos atuando dentro e fora do sistema e têm sido referidas na literatura como "Unidades de Capacidade de Recursos" (Turner \& Coffmann, 1973), "unidades ambientais" (Cendrero, 1975), entre outros termos. Tais designações têm como característica comum a diferenciação de áreas com uma certa homogeneidade interna e diferenciáveis de outras na mesma zona. Neste estudo, adotou-se o conceito de "unidades naturais" para designar estes componentes, com o objetivo de tornar mais clara a distinção de ambientes antrópi$\cos$, tais como florestamentos e áreas agropastoris, que constituem, de fato, usos das unidades naturais. Eventualmente, uma unidade natural é constituída por uma única unidade geológica/geomorfológica, p. ex., Dunas Ativas. Em outras situações, elas podem ser constituídas por duas ou mais unidades geológicas/geomorfológicas. Por exemplo, a unidade natural denominada "Planície Média" é constituída por dois terraços lagunares holocênicos distintos (T3 e T2). Embora formados em períodos diversos e apresentem cotas altimétricas distintas, tais diferenças não foram suficientes para constituir tipos de solos e padrões de vegetação e de uso do solo diferenciados, sendo, portanto, considerados como uma mesma unidade natural.

\subsection{Mapeamento e caracterização das unidades geológicas/geomorfológicas}

Adotou-se o mapeamento das unidades geológicas/geomorfológica realizado por Long (1989) 
(Figura 3), o qual foi digitalizado no ambiente SIG do Idrisi Selva. Os parâmetros empregados para caracterização das unidades geológicas/geomorfológicas incluíram: tipo de solo (Cunha, 1994); usos predominantes; cota altimétrica; nível médio do lençol freático; processos ativos dominantes e estrutura da vegetação. Na caracterização da estrutura da vegetação, foram empregados os seguintes parâmetros: fisionomia; composição florística, curva espécie-área (Muller-Dombois \& Ellenberg, 1974), densidade de cobertura vegetal (Método de Braun-Blanquet, 1979), e biomassa vegetal (peso seco) (Tabela 2). Aquelas unidades geomorfológicas que não apresentaram distinção significativa quanto à maior parte dos parâmetros analisados foram consideradas uma única unidade natural. As amostragens foram realizadas nos períodos verão e outono. Para a determinação dos parâmetros da curva espécie-área, empregou-se a técnica de amostragens de quadrantes de 0,01 a 0,025 hectares, dividindo-se em quadrantes menores de $1 \mathrm{~m}^{2}$, $4 \mathrm{~m}^{2}, 9 \mathrm{~m}^{2}, 16 \mathrm{~m}^{2}, 25 \mathrm{~m}^{2}, 36 \mathrm{~m}^{2}, 64 \mathrm{~m}^{2}, 100 \mathrm{~m}^{2}$ e $225 \mathrm{~m}^{2}$ (Westman, 1985). Foram empregadas curvas semilogarítmicas. Uma descrição mais aprofundada do método pode ser encontrada em Muller-Dombois \& Ellenberg (1974).

\subsection{Mapeamento da cobertura vegetal}

O mapeamento da vegetação foi realizado por meio de sensoriamento remoto e complementado com a verdade de campo. As comunidades vegetais terrestres foram preliminarmente definidas em função da fisionomia e descritas com base nos parâmetros acima mencionados. Foram efetuadas amostragens nos segmentos sul, mediano e norte da área de estudo, nos diferentes ambientes geomorfológicos definidos previamente por Long (1989).

\subsection{Identificação e valoração das funções e dos serviços ecossistêmicos}

As diferentes unidades naturais, previamente identificadas e caracterizadas na sua estrutura e na sua função, foram valoradas em uma escala simples de três pontos para cada função ecológica e serviços econômicos, culturais e científicos identificados. $\mathrm{O}$ nível 1 indica que determinada função ou serviço não está presente ou é pouco importante naquela unidade natural, o nível 2 indica que a função ou serviço é moderadamente importante e o nível 3, muito importante. A valoração do serviço econômico de cada um dos ambientes levou em consideração o uso econômico das atividades localizadas nos mesmos, bem como a energia teoricamente requerida para inversões de capital para o seu uso. Para as atividades econômicas que tendem a impactar a unidade natural (ex.: agricultura ou pecuária), foram atribuídos valores negativos. Os serviços culturais constituem a oportunidade de lazer e/ou cultura que os ambientes costeiros - como as dunas, lagoas, campos e as matas nativas - potencialmente ou factualmente oferecem, enquanto que os científicos constituem a oportunidade para o desenvolvimento de pesquisas científicas que certas unidades oferecem, tais como locais de ocorrência de testemunhos que podem elucidar a história geológica da região ou registros arqueológicos. Assim, os depósitos arenosos definidos por Long (1989) como Barreira II constituem um importante testemunho geológico dos eventos transgressivos marinhos que se verificaram no Pleistoceno e que resultaram na 
deposição dessa barreira arenosa. Outros ambientes de interesse científico incluem as paleodunas onde ocorrem as matas de restingas, tanto pelo seu valor geológico como pelo antropológico, pois são sítios de ocorrência de sambaquis, os quais fornecem indicações importantes sobre a antiga cultura indígena da região (Ribeiro, apud Tagliani et al., 2000).

\subsection{Categorização das classes de uso}

Por meio de uma análise de distribuição de frequência da valoração das funções e dos serviços ecossistêmicos, as unidades naturais foram agrupadas em 3 categorias de usos, que correspondem a diferentes intensidades de utilização, designadas de Zonas de Preservação, Conservação e de Desenvolvimento (Brown Jr. et al., 1974; Turner \& Coffman, 1973). Os resultados, espacializados em um mapa, constituem uma base para orientação do processo de planejamento territorial, sobre o qual outras informações podem ser adicionadas, tais como áreas sob proteção legal e outros regramentos.

\section{Resultados}

\subsection{Estrutura geológica/geomorfológica}

$\mathrm{O}$ entendimento da organização estrutural e funcional do ecossistema é fundamental para a definição de estratégias de desenvolvimento espacial ajustadas às restrições ambientais que caracterizam as zonas costeiras, particularmente as restingas. A compreensão dos processos dinâmicos que vêm atuando na sua evolução geológica está na base deste entendimento. Os sucessivos movimentos transgressivos-regressivos do nível do mar ocorridos na gênese quaternária desta planície costeira, amplamente reportados na bibliografia científica (Villwock, 1984; Long, 1989; Corrêa et al., 1992; Villwock \& Tomazelli 1995), resultaram na formação de barreiras marinhas e terraços lagunares de diferentes idades e cotas de altitude. As condições diferenciadas de atuação dos processos pedogenéticos nesses estratos, como tipo de sedimentos, tempo de atuação dos processos, geomorfologia, condições macro e microclimáticas pretéritas e ação biológica, determinaram os padrões de erosão, lixiviação, acumulação de argilas e reações químicas endógenas, resultando nos diferentes tipos de solos (Tabela 2). A complexidade geomorfológica que se verifica nessa região costeira define o padrão do mosaico ambiental, influenciando não somente na distribuição, na abundância e na diversidade da biota, mas também nos padrões de ocupação espacial e no desenvolvimento sócio econômico (Tagliani et al., 2000).

As seguintes unidades geológico-geomorfológicas foram identificadas (Figura 3) na área de estudo (Long, 1989): Dunas Ativas, Dunas Obliteradas, Mantos de Aspersão Eólica, Barreira Marinha III, Barreira Marinha II, Terraço Lagunar 5, Terraço Lagunar 4, Terraço Lagunar 3, Formação Interbarreiras.

\subsection{Vegetação}

A área de estudo encontra-se no segmento costeiro do bioma Pampa e inclui-se na região fitoecológica de Área de Formações Pioneiras (IBGE, 2018). Grande parte da área encontra-se alterada pela atividade agrícola e florestal, mas, para fins de 
TABELA 2 - Características e principais processos ativos nas unidades geomorfológicas do ecossistema da Restinga da Lagoa dos Patos.

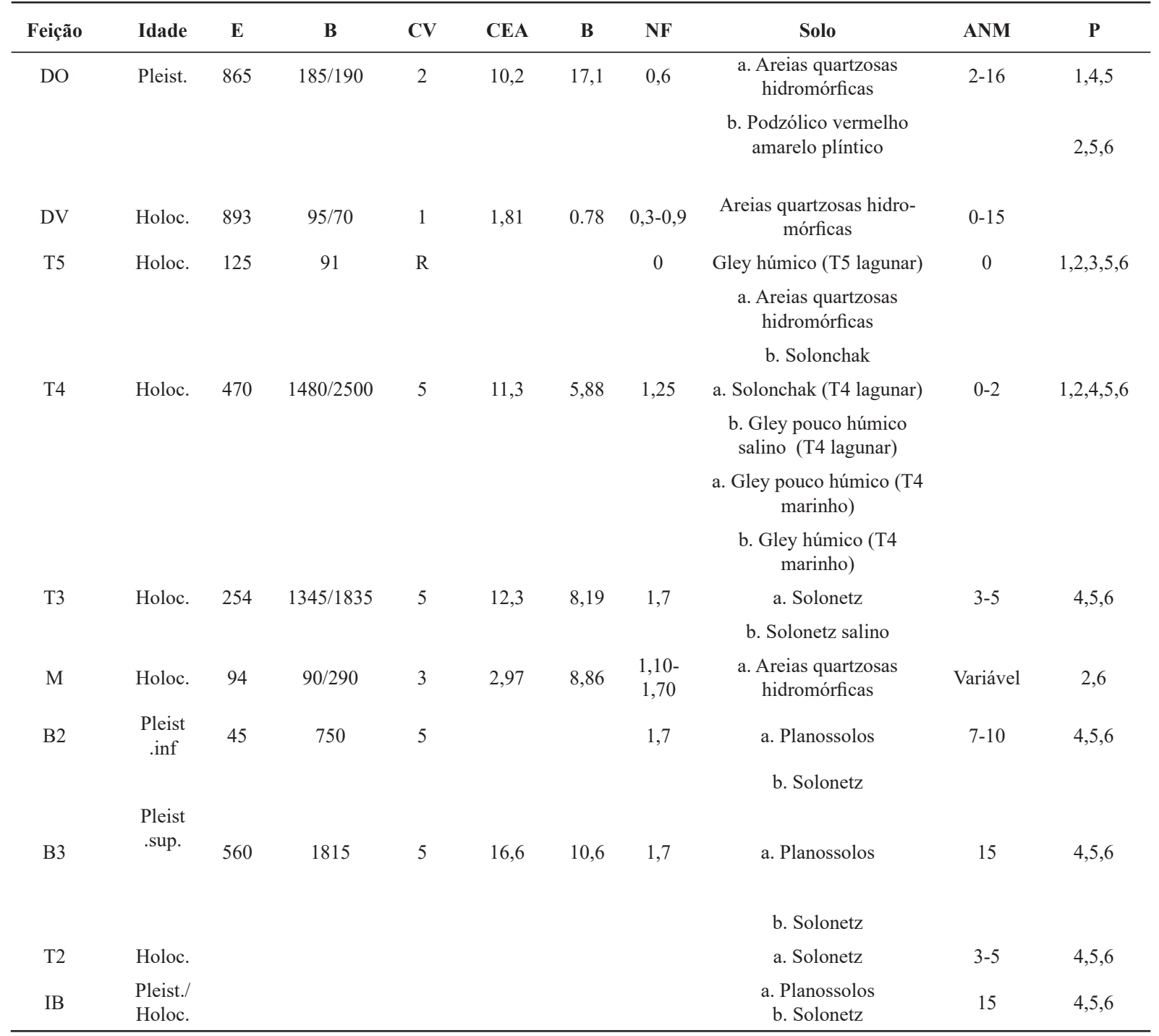

LEGENDA: E = Extensão em Km2; B= Biomassa Vegetal em g peso seco/m2 (Verão/Outono); CV= Índice de Cobertura Vegetal

(Escala de BRAUN-BLANQUET); CEA=Curva Espécie x Área (Os parâmetros a e b referem-se à curva de espécie área da equação: E = a + b $\log \mathrm{X}) ; \mathrm{NF}=$ Nível do lençol freático no verão; $\mathrm{ANM}=$ Altura média em relação ao nível do mar em metros; $\mathrm{P}=$ Processos ativos: 1) produção primária (fixação de bioenergia); 2) estocagem/transporte de sedimentos; 3) produção de detritos para cadeia trófica; 4) estocagem de nutrientes no solo; 5) Estocagem genética (biodiversidade); 6) estocagem de água. 
análise, optou-se por mapear o padrão de vegetação original, a partir da interpretação de imagens orbitais. As seguintes classes de vegetação foram estabelecidas para descrever a vegetação original desse ecossistema costeiro: Áreas de Formações Pioneiras, Campos Litorâneos, Mata de Restinga, Vegetação de banhados e Marismas (Figura 4).

Algumas unidades de vegetação correspondem aos limites das unidades geomorfológicas, como a vegetação de banhados e as matas de restinga. As mesmas foram consideradas como unidades naturais distintas, pelo fato de apresentarem diferenças marcantes nos parâmetros de vegetação analisados, tanto por sensoriamento remoto quanto por dados

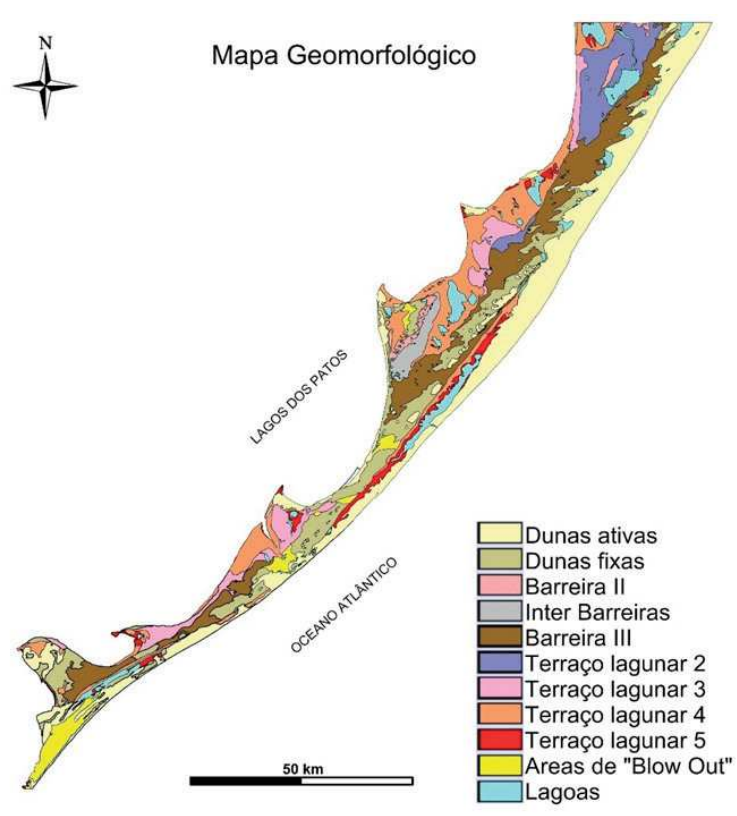

FIGURA 3 - Mapa geológico-geomorfológico da restinga da Lagoa dos Patos.

FONTE: Modificado de Long (1989). de campo. Já os Campos Litorâneos constituem formações vegetais que se estendem sobre ambientes geomorfológicos distintos, como os terraços holocênicos (T4, T3 e T2) e as barreiras pleistocênicas BII e BIII. Apesar de apresentarem características bastante semelhantes quanto à fitofisionomia e ao grau de cobertura vegetal, as diferenças, principalmente quanto a sua cota, à idade dos depósitos e tipo de solos, e à biomassa vegetal, levaram à consideração dessas feições geomorfológicas como unidades naturais distintas, denominadas de planície baixa (T4), média (T2 e T3) e alta (B3, B2 e Formação Interbarreiras). As Áreas de Formações Pioneiras são constituídas pelas unidades geomorfológicas de

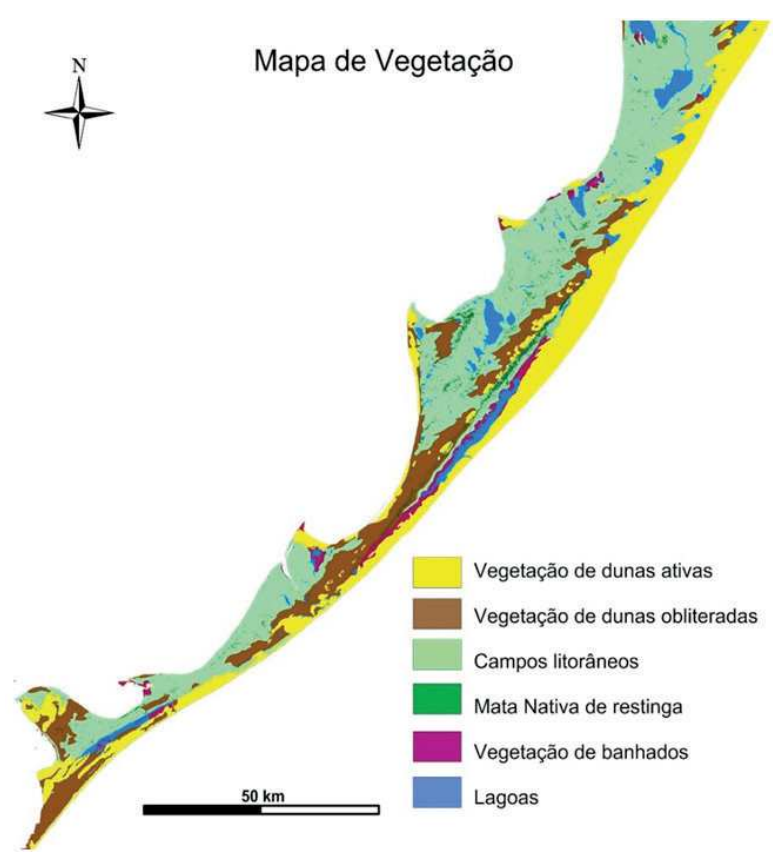

FIGURA 4 - Mapa de vegetação da restinga da Lagoa dos Patos. 
dunas ativas, dunas obliteradas e mantos de aspersão eólica. Estudos mais aprofundados podem levar a uma reconsideração da classificação proposta.

\subsection{Unidades naturais}

A Tabela 3 apresenta as unidades naturais encontradas na área de estudo, agrupadas em subsistemas ambientais, e os usos predominantes nas mesmas. Já a Tabela 4 apresenta o resultado da identificação e da valoração das funções e dos serviços presentes ou potenciais em cada unidade natural. A Figura 5 mostra a distribuição espacial dessas unidades naturais no segmento Sul da área de estudo.

\subsubsection{Zonas de desenvolvimento}

Incluem-se nesta categoria as unidades naturais com maior resiliência ambiental, ou aquelas cujas funções não são vitais para a manutenção do ecossistema, e que oferecem serviços importantes para a sociedade, como oferta de espaço para atividades agropecuárias ou mineração. As unidades naturais que integram essa categoria de uso são: Dunas obliteradas; Mantos de aspersão eólica; Planície alta e Planície média.

Essas zonas representam 55,2\% da área total do ecossistema da Restinga da Lagoa dos Patos. Os usos potencialmente adequados para essa categoria de manejo incluem turismo, agricultura intensiva (monocultura com práticas de manejo ambiental ao nível

TABELA 3 - Estrutura hierárquica da Restinga da Lagoa dos Patos e usos predominantes nas unidades naturais.

\begin{tabular}{|c|c|c|}
\hline $\begin{array}{l}\text { Sistema da Restinga da Lagoa } \\
\text { dos Patos }\end{array}$ & Unidade Natural & Usos predominantes \\
\hline \multirow{3}{*}{ Subsistema Litorâneo } & Dunas ativas & Florestamento de pinus \\
\hline & Banhados temporários & Pecuária extensiva \\
\hline & Banhados e marismas & Sem uso \\
\hline Subsistema Transicional & Mata de restinga & $\begin{array}{l}\text { Proteção ao gado, proteção às moradias, proteção de pequenas } \\
\text { lavouras (cebola), fonte de madeira }\end{array}$ \\
\hline \multirow{7}{*}{ Subsistema Lagunar } & Lagoas interiores & Irrigação, dessedentação animal, pesca esportiva \\
\hline & Banhados temporários & Monocultura de arroz em grande propriedade, pecuária extensiva \\
\hline & Planície alta (barreiras marinhas) & $\begin{array}{l}\text { Pequenas propriedades rurais (policultivo com predomínio de } \\
\text { cebola), monocultura de arroz em média propriedade, pecuária }\end{array}$ \\
\hline & Banhados permanentes & Sem uso \\
\hline & Dunas obliteradas & $\begin{array}{l}\text { Florestamento, policultivo em pequena propriedade, com predo- } \\
\text { mínio de cebola }\end{array}$ \\
\hline & Mantos de aspersão eólica & $\begin{array}{l}\text { Pequenas propriedades rurais (policultivo com predomínio de } \\
\text { cebola) }\end{array}$ \\
\hline & Praia lagunar & Lazer, pesca artesanal \\
\hline
\end{tabular}


TABELA 4 - Funções e serviços ecossistêmicos na Restinga da Lagoa dos Patos. Escala de valores e determinação das zonas de manejo recomendadas. Escala de pontuação: 1 - Pouco importante ou inexistente; 2 - moderadamente importante; 3 - muito importante.

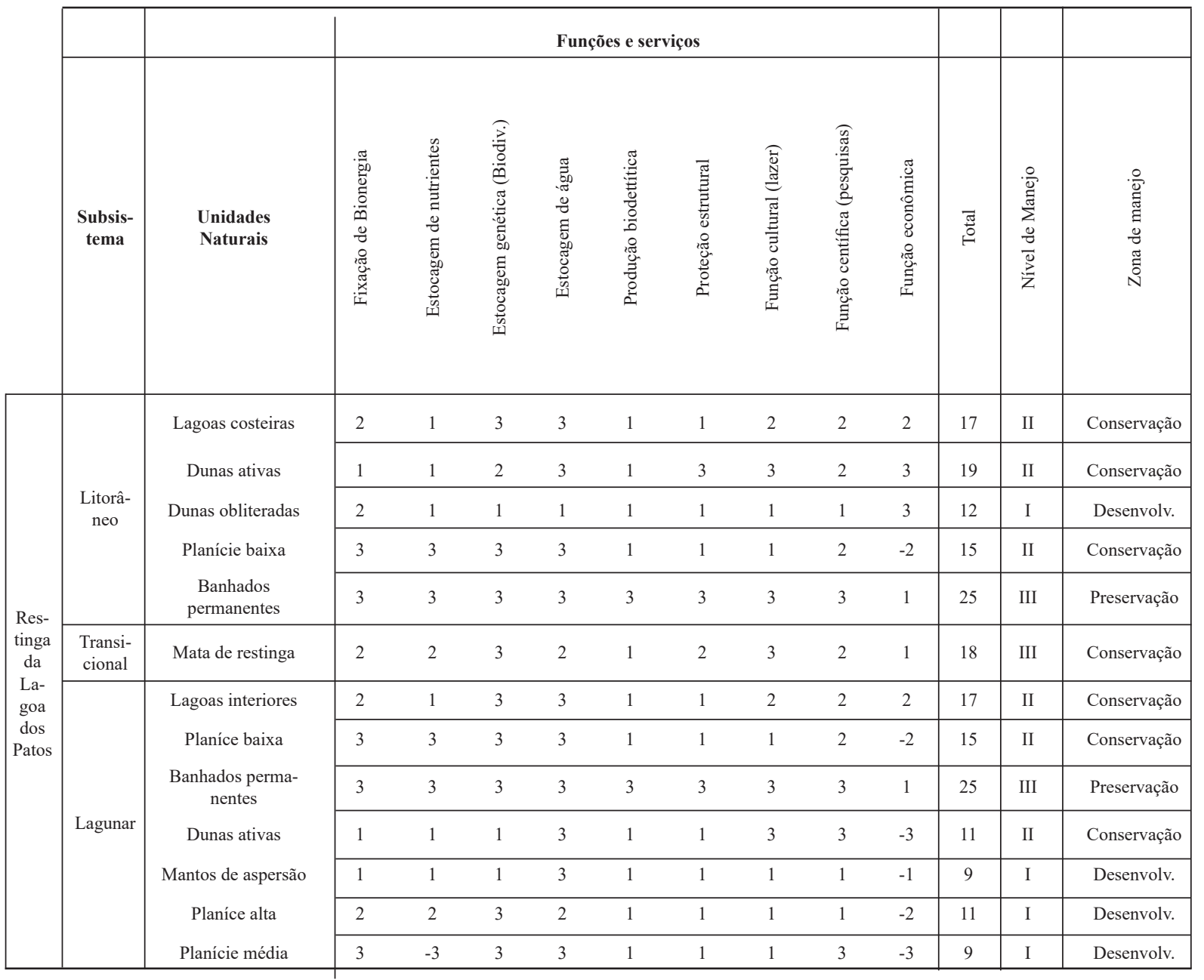

de paisagem), exploração mineral, florestamentos, pecuária extensiva, indústrias não poluidoras, estradas e assentamentos urbanos, entre outras atividades de menores restrições do ponto de vista ambiental. Usos incompatíveis: assentamentos de indústrias intensivo-poluidoras.

\subsubsection{Zonas de Conservação Ambiental}

As áreas classificadas na categoria de Conservação Ambiental admitem muitos usos que, se conduzidos de forma controlada, podem constituir importantes fontes de recursos para a região, de 


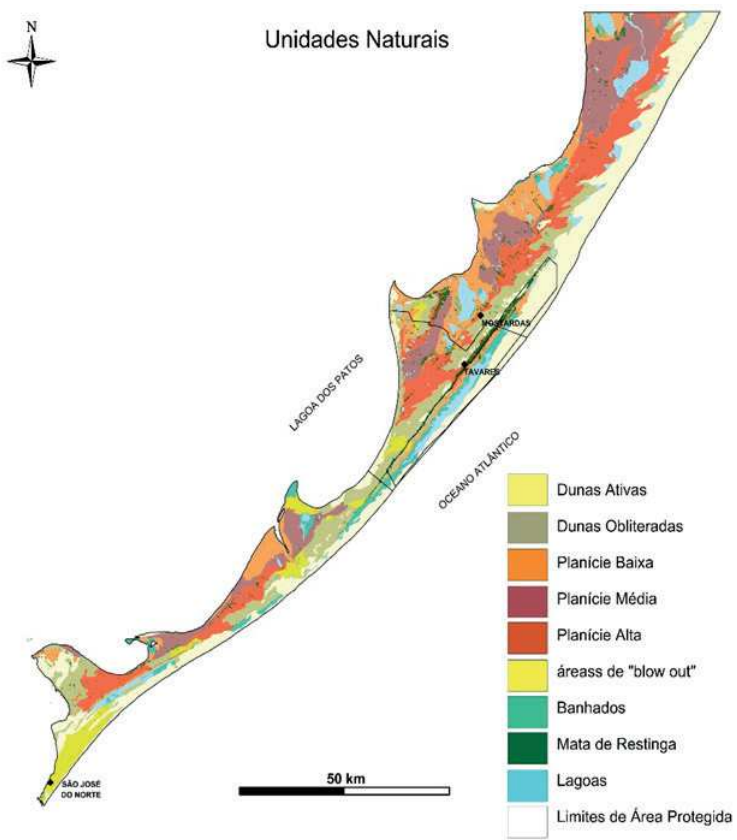

FIGURA 5 - Mapa das Unidades Naturais da Restinga da Lagoa dos Patos.

forma ecologicamente sustentável. Incluem-se nessa categoria as seguintes unidades naturais: Praia oceânica; Dunas vivas; Banhados temporários; Lagoas interiores e Planície baixa;

As Zonas de Conservação Ambiental representam $40,5 \%$ do ecossistema. Os usos potenciais de tais áreas poderiam incluir turismo controlado, agricultura diversificada sem emprego de agrotóxicos, manejo de fauna silvestre, pesca esportiva, pesca comercial e artesanal, aquacultura semi-intensiva (somente nas lagoas do subsistema Lagunar) e recreação de contato primário. Usos incompatíveis: aquacultura com espécies exóticas, assentamentos urbanos (balneários, vilas ou cidades) e industriais, florestamentos, mineração, estradas pavimentadas e tráfego de veículos. É conveniente destacar que todo o subsistema Restinga Litorâneo, que constitui os terrenos holocênicos, é considerado, de acordo com a classificação adotada, Zona de Conservação Ambiental.

\subsubsection{Zonas de Preservação Ambiental}

Essa categoria de Preservação não admite idealmente qualquer tipo de uso, a não ser a pesquisa científica não destrutiva ou atividades de lazer controladas. Incluem-se nesta os banhados permanentes, as marismas e as matas de restinga.

A proposta final de macrozoneamento para o ecossistema da Restinga da Lagoa dos Patos encontra-se na Figura 6.

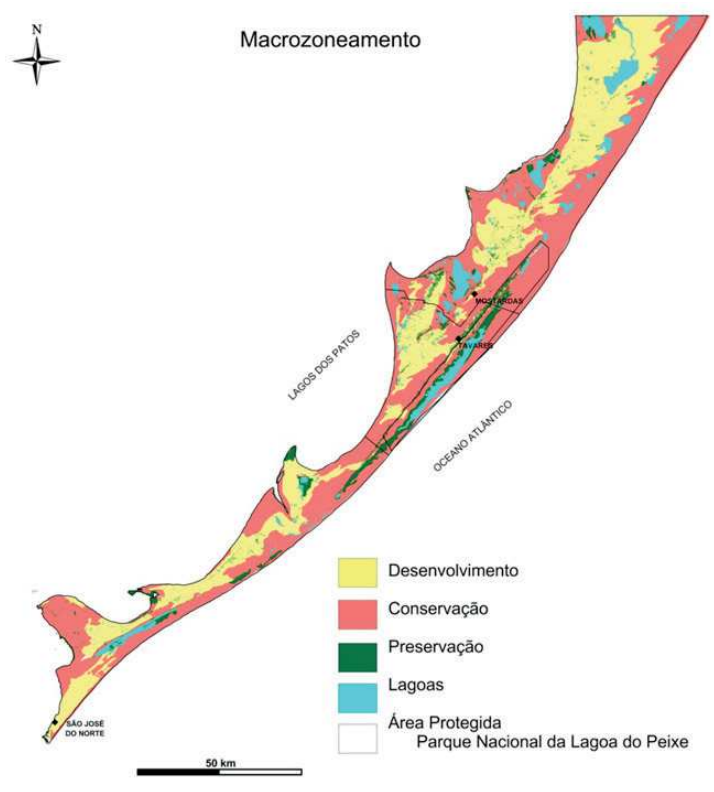

FIGURA 6 - Proposta de macrozoneamento para o ecossistema da Restinga da Lagoa dos Patos baseada na manutenção das funções e serviços ecossistêmicos. 


\section{Conclus̃̃es}

A tradução das características ambientais em funções ecossistêmicas, como recomendado por Groot (1986), mostrou-se uma excelente ferramenta para a determinação das classes de uso mais apropriadas para cada unidade natural. Esta matriz permite a otimização das funções ecossistêmicas de maneira que o máximo benefício do conjunto de funções seja alcançado, dentro dos limites de sustentabilidade ecológica, por meio do manejo integrado dos recursos.

Outra vantagem da matriz é que ela torna explícita a necessidade de adequação dos níveis de manejo (satisfação das demandas socioeconômicas) ao nível permitido pelo conjunto de funções ecossistêmicas que asseguram a sustentabilidade ecológica. A estabilidade ambiental está na base do suprimento permanente das necessidades primordiais da humanidade, como oxigênio, água, produção primária, clima, etc. De acordo com o mencionado autor, mudanças nas características causadas por atividades humanas levam a mudanças no cumprimento da função de uma determinada unidade natural ou ecossistema, resultando em mudanças na capacidade (qualidade e/ou quantidade) de uma área de sustentar certos tipos de usos do espaço.

Os resultados indicam que as zonas de Preservação e Conservação integram $44,8 \%$ da região, o que denota a importância ambiental desse ecossistema e aponta para a necessidade de orientar o modelo de desenvolvimento e de ocupação espacial na mesma observando suas características e restrições ambientais.

Antes de representar um retorno às abordagens positivistas do Ordenamento Territorial, os resulta- dos, espacializados em um Sistema de Informação Geográfica, oferecem uma base ecossistêmica para definir a capacidade de suporte do ecossistema e orientar o planejamento territorial participativo nas zonas costeiras.

Uma vez que a gênese quaternária dessa restinga está associada aos mesmos processos físicos que atuaram na formação da planície costeira do Rio Grande do Sul, propõe-se a sua aplicação em toda a extensão dessa planície, o que já foi feito no ZEE do município de Rio Grande, no estuário da Lagoa dos Patos, o qual está fundamentado sob as mesmas bases.

\section{Referências}

Braun-Blanquet, J. Fitossociologia: bases para el estudio de las comunidades vegetales. 3. ed. Madrid: Aum. Blumem, 1979.

Brown Jr., L. F. et al. Resources capability units; their utility in inland and water use management, with examples from the Texas Coastal Zone. University of Texas at Austin, Bureau of Economic Geology, Circular n 71, 22 p., 1971.

Cendrero, A. Environmental geology of the Santander Bay area, Northern Spain. Environmental Geology, 1, 97-114, 1975.

CORREA, I. C. et al. Translação horizontal e vertical do nível do mar sobre a plataforma continental do Rio Grande do Sul nos últimos 17.500 anos bp. In: III Congresso ABEQUA, Belo Horizonte - MG, Anais, 225-239. 1992.

Cunha, N. G. Caracterização dos solos de São José do Norte, Tavares e Mostardas - RS. Pelotas: EMBRAPA/ CPACT, (Série Documentos n. 7), 1994.

Fisher, B. R.; Turner, K.; Morling, P. Defining and classifying ecosystem services for decision making. Ecological Economics, 68, 643-653, 2009.

Groot, R. S. A functional ecosystem evaluation method 
as a tool in environmental planning and decision making. Netherlands: Nature Conservation Department, Agricultural University of Waneningen, 1986.

IBGE - Instituto Brasileiro de Geografia e Estatística. In: http://geoftp.ibge.gov.br / informacoes_ambientais/ vegetacao/mapas/brasil/vegetacao.pdf. Consultado em $30 / 01 / 2018$.

Lanzer, R. M.; Schäfer, A. E. Moluscos dulceaquícolas como indicadores de condições tróficas em lagoas costeiras do Sul do Brasil. Revista Brasileira de Biologia, 47(1/2), 47-56, 1987.

Loebmann, D.; Figueiredo, M. R. C. Lista dos anuros da área costeira do município de Rio Grande, Rio Grande do Sul, Brasil. Comunicações do Museu de Ciências da PUCRS, Série Zoologia, 17(2), 91-96, 2004.

Loebmann, D.; Vieira, J. P. Herpetofauna of the National Park of Lagoa do Peixe, Rio Grande do Sul, Brazil. In: Annals of Joint Meeting of Ichthyologists and Herpetologists, Manaus, 2003.

Loebmann, D.; Vieira, J. P. Relação dos anfíbios do Parque Nacional da Lagoa do Peixe, RS, Brasil. Revista Brasileira de Zoologia, 22(2), 339-341, 2005a.

Loebmann, D.; Vieira, J. P. Distribuição espacial das assembleias de peixes na Lagoa do Peixe, RS, Brasil. Revista Brasileira de Zoologia, 22(3), 667-675, 2005 b.

Loebmann, D.; Vieira, J. P. Composição e abundância dos peixes do Parque Nacional da Lagoa do Peixe, Rio Grande do Sul, Brasil e comentários sobre a fauna acompanhante de crustáceos decápodos. Revista Atlântica, 27(2), 131$137,2005 \mathrm{c}$.

Long, T. Le quaternaire littoral du Rio Grande do Sul. Temoin des quatrederniers épisodes eustatiques majeurs. Géologie et Evolution. Bordeaux, Thèse (Doctorat) - Université de Bodeaux I, n. 282. 183, 1989.

Loss, E. L. et al. Mapa geológico das folhas Lagoa dos Gateados e Farol da Solidão. Porto Alegre: CECO/IG/ UFRGS, 1985.

Loss, E. L. et al. Mapa geológico das folhas Lagoa da Reserva e Lagoa da Figueira. Porto Alegre: CECO/IG/ UFRGS, 1988.
Loss, E. L. et al. Mapa geológico das folhas Saco do Rincão e Estreito. Porto Alegre: CECO/IG/UFRGS, 1989.

Millennium Ecosystem Assessment. Ecosystems and Human Well-being: Synthesis. Washington, DC: Island Press, 2005.

Mueller-Dombois, D.; Ellenberg, H. Aims and methods of vegetation ecology. New York: John Wiley \& Sons, 1974.

Niencheski, L. F. H.; Windom, H. L. Chemistry of a Surficial Aquifer of a Large Coastal Lagoon Barrier and its Relation to Adjacent Surface Waters of Brazil. Journal of Coastal Research, 31, 1417-1428, 2015.

Scherer, A. L.; Petry, M. V. Seasonal Variation in Shorebird Abundance in The State of Rio Grande do Sul, Southern Brazil. The Wilson Journal of Ornithology, 124(1), 40-50, 2012.

Schwarzbold, A. Influência da morfologia no balanço de substâncias e na distribuição de macrófitos aquáticos nas lagoas costeiras do Rio Grande do Sul. Porto Alegre, Dissertação (Mestrado) - UFRGS, 1982.

Tagliani, P. R. A. Ecologia da paisagem da Restinga da Lagoa dos Patos: uma contribuição para o manejo e a conservação da Reserva da Biosfera. Rio Grande: Editora da FURG, 2011.

Tagliani, P. R. A.; Torres, L. H.; Alves, F. N.; Ribeiro, P. A. M. Arqueologia, história e socioeconomia da restinga da Lagoa dos Patos: uma contribuição para o conhecimento e o manejo da Reserva da Biosfera. 1. ed. Rio Grande: FURG, 2000.

Teixeira, M. B.; Neto, A. B. C. Vegetação. Levantamento de Recursos Naturais, Rio de Janeiro-RJ: SEPLAN-IBGE, 33, 541-632, 1986.

Tommasi, L. K.; Griesinger, B. Proposta para manejo correto das regiões costeiras. Ciência e Cultura, 35(6), 709-721, 1983.

Turner, A. K.; Coffman, D. M. Geology for planning: A review of environmental geology. Quart. Schools Mines, 68(3), 1-127, 1973.

Villwock, J. A. A Costa Brasileira: Geologia e Evolução. In: III Simpósio de ecossistemas da costa brasileira: subsídios a um gerenciamento ambiental. Serra Negra - SP. Anais, 
ACIESP, p1-15, 1984.

Villwock, J. A. Processos costeiros e a formação das praias arenosas e campos de dunas ao longo da costa sul e sudeste brasileira. In: Anais do Simpósio sobre Ecossistemas da Costa Sul-Sudeste Brasileira: Síntese dos Conhecimentos 1, p. 380-398. 1987.
Villwock, J. A. \& Tomazelli, L. J. Geologia Costeira do Rio Grande do Sul, Notas Técnicas. Porto Alegre, CECO/ IG/Universidade Federal do Rio Grande do Sul, 8:1- 13 45. 1995.

Westman, W. Ecology, impact assessment and environmental planning. New York: John Wiley \& Sons, 1985. 